\title{
Virtual Immersive Learning Environments (VILEs) Based on Digital Storytelling to Enhance Deeper Learning for Undergraduate Students
}

\author{
Thada Jantakoon ${ }^{1}$, Panita Wannapiroon ${ }^{1} \&$ Prachyanun Nilsook $^{1}$ \\ ${ }^{1}$ Division of Information and Communication Technology for Education, Faculty of Technical Education, King \\ Mongkut's University of Technology North Bangkok, Bangkok, Thailand \\ Correspondence: Thada Jantakoon, Division of Information and Communication Technology for Education, \\ Faculty of Technical Education, King Mongkut's University of Technology North Bangkok, Bangkok, Thailand. \\ Tel: 66-961-694-277. E-mail: thada.phd@gmail.com
}

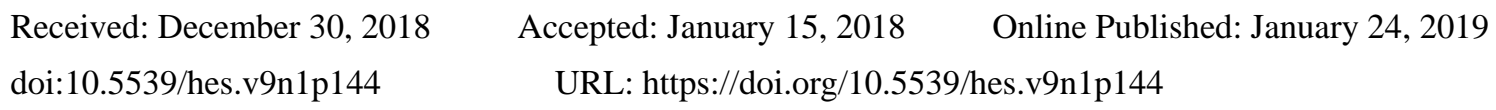

\begin{abstract}
This research aimed at proposing virtual immersive learning environments (VILEs) based on digital storytelling to enhance deeper learning for undergraduate students in all fields. The VILEs based on digital storytelling to enhance deeper learning for undergraduate students was developed based on the review of the literature, the expert's interview and evaluated by five experts. The research results were found that the VILEs based on digital storytelling to enhance deeper learning for undergraduate students consist of three components were (1) Immersive technology, (2) Digital storytelling process, and (3) Stories Evaluation. The experts also evaluated which step of the VILEs based on digital storytelling to enhance deep learning for undergraduate students was suitable for the development of the respective aspects of deeper learning.
\end{abstract}

Keywords: virtual reality, augmented reality, digital storytelling, deeper learning, virtual immersive learning environment (VILE)

\section{Introduction}

In recent years, computer and visualization technologies such as Virtual Reality (VR) and Augmented Reality (AR) have been advocated to improve construction productivity, quality, and safety. While educators may be interested in this technology, the real news is that they are also planning to invest heavily in it. According to, Goldman Sachs (2016) estimates that roughly $\$ 700$ million will be invested in AR/VR applications in education by 2025 , Virtual field trips are the only way AR and VR are active after working through some problems with WiFi networks, charging problems and the comfort level of students and teachers. Many educators find that this is the right way teaching lessons and engaging students.

Virtual environments effectively complement traditional higher education. VR technologies have been immensely used for learning professionals in high-risk occupations such as engineer, sawbones, and soldier mission. Expanding attention has also been paid to AR and its potential to improve on-site construction processes. AR supplements the physical world with interrelated synthetic data, allowing virtual and physical objects to cohabit in an augmented space area (Azuma, 1997). Numerous studies have developed AR based applications and systems for on-site tasks such as data visualization and work inspection (Park, Lee, Kwon, \& Wang, 2013). These developments have improved on-site safety performance to some scope. A few studies have also attempted to adapt VR and AR in construction training and learning.

Digital Storytelling is a modern method that is often used in learning, caused by the use of immemorial storytelling in gathering with digital multimedia. Many digital media are applied in the method of generating stories in which Digital Storytelling was used (Kotluk \& Kocakaya, 2015). Digital storytelling which has come out in recent years as an interesting learning tool (Campbell, 2012) can be used at different learning; however, it is new for undergraduate and in the procedure of upcoming (McLellan, 2006). This predicament allows for more effectual learning model. Agreeable to Hathorn (2005), Klaebe, Foth, Burgess and Bilandzic (2007) Digital Storytelling is procure together the learning skills such as digital literature in virtual learning environment with the use of digital technology and present the story in virtual Immersive learning environment.. 
Deeper learning quotes to the ability to practice that intellect to problems and situation, the merging of a deeper ability of core academic content, and the progress of a formation of capability, including human skills and selfadministration. William and Flora Hewlett Foundation has identified deeper learning as a set of capability students must master in order to increase, an intellect of academic contents and apply their intellect to problems in the learning environments and on the real world (William \& Flora Hewlett Foundation, 2013).

Virtual immersive learning environments (VILEs) is a learning scenario created using virtual reality technology or augmented reality, as well as a learning environment with simulation learning environment and virtual worlds. The important property of the VILEs based on digital storytelling to enhance deeper learning for undergraduate students is attending on active learner of VILEs in small group classes and comes from ability construction for using for deeper learning that has been authorized. The procedure of deep learning will run digital storytelling step by step, acquiring up-to-date learning and it can be practical for undergraduate in VILEs which is effectual for learning and also it is immeasurable to broadcast the learning into another science. VILEs usage is a method that promotes learner to expand deep learning and the student is able to practice learning to deeper learning efficiently. Accordingly, it is well essential to explicate deeper learning for undergraduate in all fields.

\section{Literature Review}

\subsection{Virtual Reality}

Virtual Reality (VR) is a virtual environment that is established with demonstrating an application to the user in such a way that the user promote belief and acknowledge it as an authentic environment. On a VR is basically practiced through two of the five senses: sound and sighting. The regular form of VR is a $3 \mathrm{D}$ animation that can cause interactively at a mobile computer, commonly by a handle or the remote control so that the image of the digital content shift in some setting (Yasin, Darleena, Mohd, \& Mohd, 2012). VR represents a novel move to a more complete sensorial involvement; it has been the subject of several applications in higher education, and professional development (Freina \& Ott, 2015).

\subsection{Augmented Reality}

Augmented reality (AR) is a mixed environment which mixes virtual and physical environments in immediately. Appliance-based on this technology feel on three bases: tools to track information about physical environments of liking; software and hardware to system computer; and devices to show the human the virtual environment integrated into the physical environments (Webster, 2016). AR technology is frequently illustrated with reference to its two special forms of behaving data from the physical world. The first is an AR marker, which demands retirement of a marker to take virtual data; the second is AR location-based, which makes use of a GPS location-based to analyze locality at where virtual object data should be overlap.

\subsection{Digital Storytelling}

There have been many definitions of digital storytelling in related literature. Robin and Pierson (2005) highlighted that digital storytelling is the work of creating purposive scenes that reflect personal idea. Digital stories can have an aim of informative and individual imparting (Robin, 2008). Porter (2004) described storytelling as compound real stories with virtualization, sound effect, video, and graphic while Dupain and Magure (2005) defined it as creating a story by collect hardware, software, and stories elements such as 3D animation, sound, photo, and video as nice as Chung (2007) noted it as a harmonic digital media composed of multimedia components such as video, photo, audio, text, and 3D model. However, digital storytelling is full regard as creating stories some topics by use software tools and for generating and distributing this story in the virtual environment (Nguyen, 2011). Practically all digital stories are ground via union constitutive with a true story on an individual topic.

\subsection{Deeper Learning}

Deeper learning contains three domains (Pellegrino, Hilton, \& Herman, 2012).

2.4.1 Cognitive: Students extend a strong academic foundation on topics such as art, mathematics, science and technology. Highly important, they know the principles and concepts. As a main content learner, they can connect to learning more with work or other tasks. Students will learn how to think critically. That is, they will have the potential to analyze and synthesize the question frame data; and accept patterns, trends and relationships so that they can explore and solve problems thoroughly according to estimates or assessments of the proposed solutions

2.4.2 Interpersonal: Students learn how to work together to work to finish, understand and solve complex problems and produce shared work. They also learn how to communicate complex concepts to others effectively 
through various expression modes in a useful, logical, meaningful and objective way. In order for students to do this, they must learn how to clearly organize things, discover their information and ideas.

2.4.3 Intrapersonal: Students learn how to control their own learning and examination, recognize what they know or remember when and how they are confused, identify obstacles or obstacles to their success. In developing academic thinking, students can see themselves as academic successes and feel strong performance and believe in their abilities. As a result, students participate in positive and effective academic behavior and endure when they experience problems.

\section{Method}

This research is divided into 2 steps: (1) The study that related to theories, research and experts' opinion, (2) Evaluation on the proposed learning environments.

\subsection{Phase 1: The Study that Related to Theories, Research, and Experts'Opinion}

The study in this phase included the study of theories and research on the VILEs, digital storytelling, and deeper learning to be used as guidelines in determining learning processes and components of the learning environments. The learning environments will be designed after documentation review, and then the interview will be conducted to get an opinion towards the learning environments from five experts.

\subsection{Phase 2: Evaluation on the Proposed Learning Environments}

After gathering all of information and modifying the learning environments, three educational technology experts and two deeper learning experts were selected to evaluate the learning environment by using five scales learning environment evaluation form. The expert selection criteria consisted of (1) the experts must have more than three years of experiences in the educational technology / deeper learning field, (2) the experts must have a related work in educational technology /deeper learning field, and (3) the experts must have experiences in designing learning environments or teaching with undergraduate students.

\section{Results}

4.1 Phase 1: Results of the proposed learning environments, the results can be seen in Figure 1.

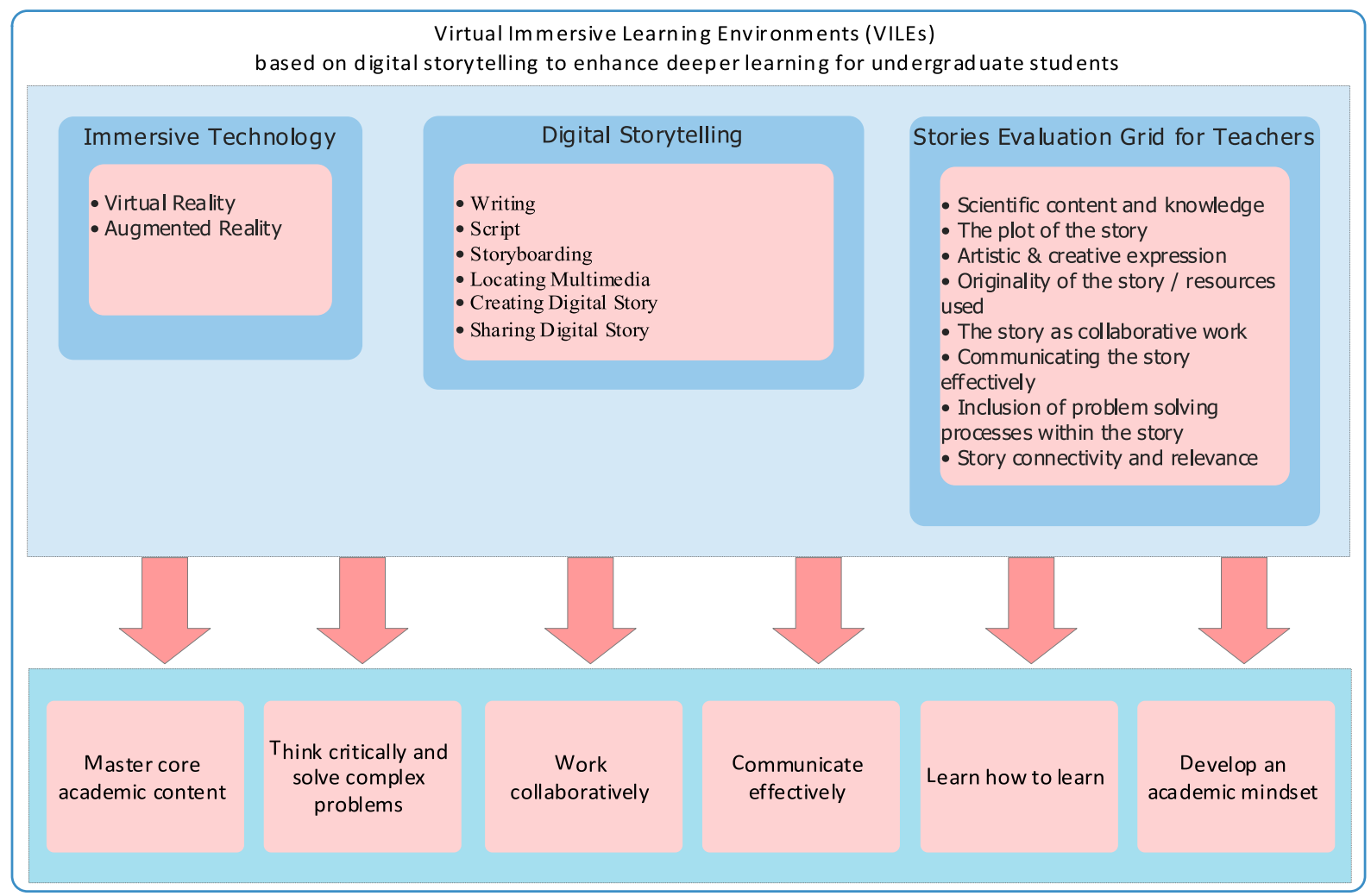

Figure 1. VILEs based on digital storytelling to enhance deeper learning for undergraduate students 


\subsubsection{Immersive Technology Includes:}

4.1.1.1 VR refers to "virtual learning environments that motivate the real owning of human or thing and substantive sensory ways" (Adams, Freeman, Giesinger, Cummins, \& Yuhnke, 2016). It uses 3D animation interactions that users can experience with the keyboard and mouse or with a headset designed to immerse users in realistic virtual environments. In addition, some recent applications also allow users to "feel" and interact with objects via forced feedback. To date, applications that are commonly used for VR tools have been trained and learned in the learning environment.

4.1.1.2 AR has the potential for teaching (Chujitarom \& Piriyasurawong, 2017). There are various tools for working with AR capabilities. The lowest level method provides a complex set of tools, libraries and scripting frameworks for application developers. Examples of such tools are ARToolKit, ArUco or Vuforia SDK. These help develop powerful and customizable AR applications. But they need high knowledge in programming languages such as $\mathrm{C}++$, Java or JavaScript. On the other hand, there are many higher level graphical writing tools on the internet.

\subsubsection{Digital Storytelling Process Includes:}

The process of creating a digital story is described in six steps (Jakes \& Brennan, 2005):

4.1.2.1 Writing: In this step, the draft of the script has been developed and then will be reviewed and discussed by others. The creator or author begins by searching for topics for the story. Finally, the draft of the script is completed according to comments and assessments.

4.1.2.2 Script: This script also defines the multimedia elements that will be used in the stories and how to use these multimedia components. In this sense, the script is considered the basis of digital stories.

4.1.2.3 Storyboarding: The aim of the storyboard process is to see how the movie or digital story will work. Storyboard boards are plans for changing scenes, sequences and effects. The storyboard is used for planning the unity of videos, images, sounds and three-dimensional images (Lambert, 2010).

4.1.2.4 Locating Multimedia: This step can be defined in two steps (a) to complete the storyboard; the author will search for multimedia components. (Graphics, sounds, animations, videos, photos, music, etc.) to be used to increase the efficiency of the script using online sources and drafting in print To a USB flash drive (b) after that will record voice It should be focused and emotional

4.1.2.5 Creating Digital Story: The digital story is produced using various technologies and software. All components such as videos, music, 3D animations and photos are combined. In order to create digital stories, all components are linked to each other to organize a smooth VR / AR.

4.1.2.6 Sharing Digital Story: For this step, the most important step will be to share digital stories with people in the social classroom or VR / AR classroom, such as generate QR code, Facebook, YouTube, Twitter and so on. Comment from the audience.

\subsubsection{Stories Evaluation (Koerner \& Otto, 2017):}

4.1.3.1 Scientific content and knowledge: Deep stories in the scientific theory show that will be confirmed; Facts about missions that reflect current scientific knowledge Types of scientific data to be analyzed and compiled or summaries that will be used within the story.

4.1.3.2 The plot of the story: To what extent scientific vocabulary is used in the plot. How much each story reflects upon students creative thinking skills. How does the story flow and if it makes a functional use of the language.

4.1.3.3 Artistic and creative expression: The quality of artistic expression or artistic content created by students indicates that students enjoy working together and presenting their creations or knowledge in a non-routine manner.

4.1.3.4 Original of the story: Traditional methods in selected themes if the original source is developed or created by students for the purpose of the subject.

4.1.3.5 The story as collaborative work: Effective methods and the number of members of each team working together.

4.1.3.6 Communicating the story effectively: The story style is sent to friends not only speaking but also using other forms of non-verbal transmission or body language to be evaluated according to its effectiveness.

4.1.3.7 Inclusion of problem solving processes within the story: If the related problems are different, the students 
should be advised and corrected in each issue. The more challenging topics are chosen, the knowledge of the key principles associated with the problem is the key.

4.1.3.8 Story connectivity and relevance: The story is created in different episodes and the inclination of the story as it moves from one scene to another, should be completed.

4.1.4 Deeper Learning (William \& Flora Hewlett Foundation, 2013) (Chow, 2010):

4.1.4.1 Master core academic content. Students emerge and explain from a basic understanding of academic discipline and can send knowledge to other situations

4.1.4.2 Think critically and solve complex problems. Students use techniques and software from core subjects to solve problems and determine these tools include data analysis, scientific inquiry and statistical reasoning, including creative persistence and problem solving.

4.1.4.3 Work collaboratively. Students gather to identify and create solutions for communities, societies, and academic, personal and undergraduate challenges.

4.1.4.4 Communicate effectively. Students clearly organize information, ideas and research results in both speaking and writing.

4.1.4.5 Learn how to learn. Students are directed to monitor learning by themselves.

4.1.4.6 Develop academic mindsets. Students expand their beliefs about themselves and positive attitudes as learners that increase academic diligence and encourage them to participate in effective academic behavior.

\subsection{Phase 2: Evaluation on the Proposed Learning Environments}

The evaluation scores of the proposed learning environments from three educational technology experts and two deeper learning experts were summarized in Table 1.

Table 1. Experts' evaluation scores of the proposed learning environments

\begin{tabular}{lccl}
\hline Evaluation Lists & \multicolumn{2}{l}{ Results } & Appropriateness \\
\cline { 2 - 3 } & $\overline{\mathrm{X}}$ & S.D. & \\
\hline Objective of the Learning Environments & 4.60 & 0.51 & Strongly agree \\
Uses of Concepts and Principle & 4.70 & 0.48 & Strongly agree \\
Components of Learning Environments & 4.20 & 0.42 & Agree \\
Process of Learning & 4.40 & 0.54 & Agree \\
Easy to Understand & 4.50 & 0.52 & Strongly agree \\
Overall & 4.48 & 0.49 & Agree \\
\hline
\end{tabular}

In Table 1, the research found that the VILEs based on digital storytelling to enhance deeper learning for undergraduate students was evaluated at the strongly agree level in objective of the learning environments, uses of concepts, and easy to understand. Components of learning environments and process of learning were at the agree level. The objective of the learning environments to enhance deep learning for undergraduate students. Concepts and Principle can be categorized into VR, AR, Digital Storytelling, and deeper learning. Components of learning environments can be subdivided immersive technology, digital storytelling, stories evaluation, and deeper learning. Examples of process of learning comprise six steps are writing, script, storyboarding, locating multimedia, creating digital story, and sharing digital story. The VILEs based on digital storytelling to enhance deeper learning for undergraduate students showed overall results at agree level (arithmetic mean $=4.48$, standard deviation $=0.49$ ).

\section{Conclusion}

According to the document analysis that was associated with the process of VILEs and digital storytelling, together with deep learning for undergraduate students, it was found that the VILEs based on digital storytelling to enhanced deeper learning for undergraduate students in all fields. Immersive technology consists of two components: 1) VR: high-immersion virtual reality environments leads to higher levels of presence, and ultimately better learning and transfer outcomes; and little is known about how different levels of immersion affect cognitive load and ultimately learning and transfer outcomes; and 2) AR: AR is helpful in increasing students' motivation, fostering collaboration among students, developing spatial abilities, and improving performance in physical tasks. Digital storytelling process comprises eight steps: 1) Writing; 2) Script; 3 ) Storyboarding; 4) Locating Multimedia; 5) Creating Digital Story; and 6) Sharing Digital Story. Stories Evaluation consists of aspects steps: 1) Scientific content and knowledge; 2) The plot of the story; 3) Artistic and 
creative expression; 4) Original of the story; 5) The story as collaborative work; 6) Communicating the story effectively; 7) Inclusion of problem solving processes within the story; and 8) Story connectivity and relevance.

\section{Acknowledgments}

This research was funded Capacity Building Program for New Researcher 2018 from, National Research Council of Thailand (NRCT).

\section{References}

Adams, B. S., Freeman, A., Giesinger, H. C., Cummins, M., \& Yuhnke, B. (2016). NMC/CoSN Horizon Report: 2016 K-12 Edition. Austin, Texas: The New Media Consortium.

Azuma, T. R. (1997). A survey of augmented reality. Presence, 6, 355-385. https://doi.org/10.1162/pres.1997.6.4.355

Campbell, T. (2012). Digital Storytelling in an elementary classroom: Going beyond entertainment. Procedia Social and Behavioral Sciences, 69, 385-393. https://doi.org/10.1016/j.sbspro.2012.11.424

Carnavale, A. P., \& Rose, S. J. (2015). The Economy Goes to College: The Hidden Promise of Higher Education in the Post-Industrial Service Economy. Washington, D.C.: Georgetown University Center on Education and the Workforce

Chujitarom, W., \& Piriyasurawong, P. (2017). Animation Augmented Reality Book Model (AAR Book Model) to Enhance Teamwork. International Education Studies, 10(7), 59-64. https://doi.org/10.5539/ies.v10n7p59

Chung, S. K. (2007). Art education technology: Digital storytelling. Art Education, 60(2), 17-22. https://doi.org/10.1080/00043125.2007.11651632

Chow, B. (2010). The quest for deeper learning. Education Week. Retrieved from http://www.hewlett.org/newsroom/news/quest-deeper-learning-barbara-chow

Dupain, M., \& Maguire, L. (2005). Digital storybook projects 101: How to create and implement digital storytelling into your curriculum. 21st Annual Conference on Distance Teaching and Learning.

Freina, L., \& Ott, M. (2015). A Literature Review on Immersive Virtual Reality in Education: State Of The Art and Perspectives. In Proceedings of eLearning and software for education, 133-141.

Goldman, S. (2016). The real deal with virtual and augmented reality. Retrieved from http://www.goldmansachs.com/our-thinking/pages/virtual-and-augmented-reality.html

Hathorn, P. (2005). Using Digital Storytelling as a literacy tool for the inner city middle school youth. The Charter Schools Resource Journal, 1(1), 32-38.

Jakes, D.S. \& Brennan, J. (2005). Capturing stories, capturing lives: An Introduction to digital storytelling. Retrieved from http://bookstoread.com/etp/earle.pdf

Klaebe, H., Foth, M., Burgess, J., \& Bilandzic, M. (2007). Digital Storytelling and history lines: community engagement in a master-planned development. In Proceedings 13th International Conference on Virtual Systems and Multimedia. Brisbane.

Koerner, F., \& Otto, S. (2017). STORIES OF Students' Visions on the Future of Space Exploration, Assessment Tools. ELLINOGERMANIKI AGOGI, 13-15 Retrieved from http://www.storiesoftomorrow.eu/sites/default/files/Assessment\%20Tools.pdf

Kotluk, N., \& Kocakaya, S. (2015). 21.yüzyıl becerilerinin gelişiminde dijital öykülemeler: ortaöğretim öğrencilerinin görüşlerinin incelenmesi. Eğitim ve Öğretim Araştırmaları Dergisi, 4(2), 354-363.

Lambert, J. (2010). Digital storytelling cookbook and traveling companion. Berkeley, CA: Digital Diner Press.

McLellan, H. (2006). Digital Storytelling in higher education. Journal of Computing in Higher Education, 19(1), 65-79. https://doi.org/10.1007/BF03033420

Nguyen, A. T. (2011). Negotiations and challenges in creating a digital story: The experience of graduate students. Dissertation (Ed. D.), University of Houston.

Park, C. S., Lee, D. Y., Kwon, O, S., \& Wang, X. (2013). A framework for proactive construction defect management using BIM, augmented reality and ontology-based data collection template, Automation in Construction, 33, 61-71. https://doi.org/10.1016/j.autcon.2012.09.010

Pellegrino, J., Hilton, M., \& Herman, J. (2012). Education for Life and Work: Developing Transferrable Knowledge and Skills in the 21st Century. Washington, D. C.: National Research Council. 
Porter, B. (2004). Digitals: The art of telling digital stories. USA: Bernajean Porter Consulting.

Robin, B., \& Pierson, M. (2005). A multilevel approach to using digital storytelling in the classroom. In C.

Robin, B. (2008). The effective uses of digital storytelling as a teaching and learning tool, Handbook of research on teaching literacy through the communicative and visual arts New York. Lawrence Erlbaum Associates.

Webster, R. (2016). Declarative knowledge acquisition in immersive virtual learning environments. Interactive Learning Environments, 24(6), 1319-1333. https://doi.org/10.1080/10494820.2014.994533

William \& Flora Hewlett Foundation. (2013). Deeper learning defined. Retrieved from http://www.hewlett.org/library/hewlett-foundation-publication/deeper-learning-defined

Yasin, M. A., Darleena, Z., Mohd, A., \& Mohd, I. (2012). Avatar Implementation in Virtual Reality Environment using Situated Learning for "Tawaf”. Procedia - Social and Behavioural Sciences, 67, 73-80.

https://doi.org/10.1016/j.sbspro.2012.11.308

\section{Copyrights}

Copyright for this article is retained by the author(s), with first publication rights granted to the journal.

This is an open-access article distributed under the terms and conditions of the Creative Commons Attribution license (http://creativecommons.org/licenses/by/4.0/). 